\title{
Inclusão na língua: as tentativas de neutralidade de gênero no português brasileiro
}

\author{
Veridiana de Souza GUIMARÃES (1) \\ Universidade de Santa Cruz do Sul (UNISC)
}

\section{RESUMO}

A presente resenha aborda as principais questões acerca do simpósio Língua, gramática, gênero e inclusão, que ocorreu no dia 14 de julho de 2020, às 19 horas, na série de conferências organizadas pela Associação Brasileira de Linguísticas (Abralin), durante a pandemia de COVID-19. No encontro do dia 14, particularmente, discutiu-se acerca da dúvida: o português é uma língua que privilegia o gênero gramatical masculino? Diante disso, o objetivo dessa resenha é apresentar e discutir acerca das tentativas de inclusão de gênero neutro no português, uma vez que o português é uma língua binária. Nesta perspectiva de fala, Luiz Schwindt, Pedro Sur-

OPEN ACCESS

EDITADO POR Raquel Freitag

AVALIADO POR Bruno Pinheiro

DATAS Recebido: 27/07/2020 Aceito: $13 / 08 / 2020$ Publicado: 02/10/2020 reaux, Bruno Felipe Marques Pinheiro, Andrei Ferreira de Carvalho Pinheiro e Ana Paula Rabelo apresentaram as suas pesquisas e reflexões acerca da temática língua, gramática, gênero e inclusão. O simpósio também contou com a colaboração da mediadora Raquel Freitag.

\section{ABSTRACT}

This review addresses the main questions about the symposium Language, grammar, gender and inclusion, which took place on July 14, 2020, at 7 pm, in the series of conferences organized by the Brazilian Association of Linguistics (Abralin), during the COVID-19 pandemic. At the meeting on the 14th, in particular, the question was discussed: is Portuguese a language that favors the male grammatical gender? Therefore, the purpose of this review is to present and discuss attempts to include gender neutrality in Portuguese, since Portuguese is a binary language. In this perspective of speech, Luiz Schwindt, Pedro Surreaux, Bruno Felipe Marques Pinheiro, 


\section{REVISTA DA ABRALIN}

Andrei Ferreira de Carvalho Pinheiro and Ana Paula Rabelo presented their research and reflections on the theme language, grammar, gender and inclusion. The symposium also had the collaboration of the mediator Raquel Freitag.

PALAVRAS-CHAVE

Abralin. Gênero. Inclusão.

KEYWORDS

Abralin. Genre. Inclusion.

\section{Para início de conversa}

"Línguas codificam experiências no mundo por diferentes caminhos (..). Na representação de gênero, as línguas do mundo tendem a estabelecer uma relação com sexo, assumindo em geral como padrão o masculino". Essa citação descreve a fala proferida pela mediadora do simpósio Língua, gramática, gêenero e inclusão, a professora Raquel Freitag. Por meio da introdução da mediadora Raquel, o debate foi direcionado a discussão: O português é uma língua que privilegia o gênero gramatical masculino? Se sim, quais as alternativas para promover a inclusão de gêneros sociais menos favorecidos ou até mesmo não contemplados? Diante isso, podemos afirmar que existe gênero neutro em português?".

É importante falar sobre o desequilíbrio existente nas sociedades, sendo a desigualdade responsável pela exclusão de alguns grupos sociais. Dentre as formas de desigualdade está a de gênero, estruturada nas distinções sociais e culturais entre homens e mulheres. Assim, impulsionado pelo movimento feminista dos anos de 1960, surge o campo de estudo sobre gênero e língua para identificar as variedades linguísticas específicas para cada gênero e ainda para entender como a língua pode ser desviante e excludente. Em um segundo momento, mais recentemente, a reflexão vai além de um pensamento estritamente binário de construção de gênero linguístico e amplia-se o campo de estudo para incluir as discussões de desejo e identidade sexual. Dessa forma existem inúmeros movimentos sugerindo recursos gramaticais capazes de subverter a tendência masculina na língua, propondo alternativas para uma possível linguagem inclusiva. Existem grupos que defendem os sistemas sem marcação ou mesmo com marcação dupla ou neutra de gênero. Dentre os recursos já existentes e mobilizados em prol de uma linguagem neutra estão: @, x, e, ile, illus. Dito isso, a presente resenha busca apresentar algumas das tentativas de inclusão de gênero neutro no português. 


\section{REVISTA DA ABRALIN}

\section{Língua, gramática e gênero e inclusão}

Muitas línguas, como a portuguesa, apresentam uma predominância do gênero masculino no discurso sendo que, em um grupo constituído por várias mulheres e apenas um homem é, geralmente, referido pelo pronome pessoal masculino "eles", desconsiderando a presença do feminino no discurso. Além do discurso masculinizante, o português apresenta uma binariedade no gênero de seus pronomes, os masculinos e os femininos. Por essa razão, algumas pessoas, especialmente da comunidade trans, não se reconhecem em termos de gênero e identidade, obrigando-as a se limitar ao uso de um pronome com o qual não se identificam. Assim, por considerarem a língua sexista, grupos e ativistas defendem o uso e a implantação do pronome neutro na língua portuguesa.

Para entender o que vem sendo pesquisado sobre a temática língua e inclusão, apresento, pela ordem das apresentações, as reflexões oriundas do simpósio Língua, gramática, gênero e inclusão, organizado pela Abralin. Então, após a fala introdutória da mediadora Raquel Freitag, foi a vez do professor e pesquisador da Universidade Federal do Rio Grande do Sul, Luiz Schwindt, discutir a possível existência do gênero neutro em português. O simposiasta dividiu a sua apresentação em quatro etapas: contextualização, mudança morfológica, produtividade de "-e" e gênero neutro no português brasileiro. Na parte da contextualização, o professor fez um breve apanhado sobre os diferentes olhares sobre o gênero no português. Segundo ele, dentre as tentativas de neutralização da língua, temos duas: (i) o uso de @ e o "x"; (ii) e o uso de “-e". No entanto, enfatizou que o @ e o "x" apresentam sérios problemas no que se refere a pronúncia (fala) e ao acesso as pessoas com deficiência. Apesar de não haver uma alternativa 100\% eficaz, entre as propostas inovadoras de neutralização de gênero no português brasileiro, Luiz sugeriu a utilização do expoente -e. Segundo ele, essa é a que merece maior atenção. Assim como em toda a sua fala, explicou o porquê dessa afirmação: a perda de eficiência dos demais neutralizadores (@ e X, por exemplo) estaria ligada, principalmente, à falta de equilíbrio entre a fala e a escrita, ou vice e versa. O único problema da utilização do expoente "-e" estaria relacionada à perda do contraste. Em suas palavras, apesar da importante motivação extralinguística (social e cognitiva), o -e tem poucas chances de assumir o status de neutro no português, pois não apresenta contraste morfofonológico robusto.

Para fundamentar as explicações sobre as tentativas de usos de gênero neutro no português, Luiz Schwindt apresentou uma pesquisa envolvendo substantivos do português brasileiro (Dicionário Aurélio, do Projeto Varsul e do Projeto Aspa). Segundo os dados do estudo, há mais substantivos uniformes femininos do que substantivos masculinos, ou seja, há mais palavras femininas do que masculinas. Ainda sobre a pesquisa com palavras e análise de gênero, apenas 4,9\% se sujeitam à oposição entre masculino e feminino (menino/a; professor/a, o/a dentista). Apesar de poucos numerosos, os substantivos biformes sexuados que opõem -a e -o apresentam forte prevalência do masculino no uso: $5,2 \%$ contra $2,7 \%$, fato que, segundo Schwindt, colabora com a impressão masculinizante da língua.

Na sequência, Pedro Surreaux, também da Universidade Federal do Rio Grande do Sul, começou a sua apresentação ao afirmar que os substantivos em português possuem gênero gramatical por 


\section{REVISTA DA ABRALIN}

conta da morfossintaxe (concordância). Em sua fala, Surreaux afirma que: "no caso, dentro do contexto sintático, não tem como o substantivo não ter gênero, apesar de não aparentar, na maioria das vezes, essa característica". Em sua pesquisa "Critérios para atribuição de gênero em empréstimos do inglês ao português brasileiro" considera que: critérios de motivação semântica predominam dentre os critérios de atribuição de gênero a empréstimos do inglês em português brasileiro: a fonotática do inglês limita o número de empréstimos terminados por vogais átonas e, por consequência, restringe a aplicação de critérios formais. A maioria dos itens femininos tem final "-e", sendo que a maioria das palavras terminadas em "-e" se configura como elemento epentético.

Na sequência da fala, Bruno Felipe Marques Pinheiro, da Universidade Federal de Sergipe, apresentou a sua pesquisa "Estereótipos na concordância de gênero em profissões: efeitos de frequência e saliência". Para verificar a relação entre os estereótipos e gêneros na língua, o pesquisador realizou um teste experimental, por meio do software Psychopy, no qual elaborou uma tarefa de julgamento social com estudantes universitários, em uma escala de 1 a 7 pontos com grau de feminilidade ou masculinidade, de 30 profissões pré-selecionadas. Entre os resultados obtidos, Pinheiro afirmou que taxista, motorista, eletricista e fiscal de obra são profissões vinculadas ao alto grau de masculinidade, ou seja, são profissões vistas como mais masculinas, enquanto a profissão de babá estaria ligada ao alto grau de feminilidade, devido ao fato de estar ligada as tarefas domésticas realizadas por mulheres. Segundo o pesquisador, "a gente observa que a marcação de gênero explicita a informação gramatical a partir da representação dos estereótipos construídos". Assim, Bruno comentou que determinados grupos, ativistas de movimentos feministas e LGBTQI+ defendem uma linguagem neutra ou não binária. Essas pessoas, segundo o simposiasta, querem descaracterizar o binarismo e a perpetuação dos estereótipos de gêneros clássicos. Para ele, esse pensamento tem ganhado muita força no Brasil, principalmente a partir do ano de 2016, quando a empresa Avon lançou uma campanha publicitária pensando nessa temática. "Para todes!, Avon lança campanha sem gênero para maquiagem e viraliza nas redes sociais". Outro argumento apresentado pelo pesquisador é a modificação de documentos oficiais. "Temos a lei $\mathrm{n}^{\circ} 12605$ de 3 de abril de 2012, que normaliza o direito de as mulheres terem seus diplomas flexionados com o gênero gramatical correspondente aos seus gêneros biológicos".

A penúltima apresentação foi de Andrei Ferreira de Carvalho Pinheiro, da Universidade Federal do Rio de Janeiro, o qual apresentou seu estudo em que problematiza os conceitos de "puto" e "puta". Para ele, existe um desequilíbrio entre os dois termos: enquanto "puto" remete ao significado de estar irritado, a palavra "puta" associa à mulher a uma profissional do sexo. Diante da fala de Pinheiro, lembrei-me de mais alguns exemplos em que a palavra feminina é utilizada pejorativamente. Podemos citar aqui a diferença entre boi/vaca, galo/galinha, por exemplo, que relaciona a figura feminina a um significado negativo e a masculina a um significado positivo (que enaltece a sua masculinidade). Em sua fala final, o pesquisador firmou que os usos de "puto" e "puta" evidenciam que, pela língua, mantemos uma hierarquia binária e sexista de gênero.

A última apresentação foi da professora Ana Paula Rabelo, da Universidade Estadual do Ceará. De início, a professora apresentou seu interesse de estudo e afirmou que as mudanças de mentalidade passam pelo trabalho a ser realizado nas escolas. Segundo ela, "é nas escolas que podemos 


\section{REVISTA DA ABRALIN}

legitimar mudanças que estão acontecendo na sociedade". Apesar de ter iniciado sua apresentação, Ana Paula foi prejudicada pela conexão de internet que a impediu de continuar a discussão.

A fim de dar prosseguimento ao evento, a mediadora Raquel disponibilizou o espaço final para a reflexão acerca das perguntas e afirmações feitas no chat. Sobre a pergunta "Há a possibilidade de consolidação de um gênero neutro no português brasileiro?", o linguista Luiz Schwindt afirmou que "Sim, pode existir, pois a língua é muito rica e com muita potência de mudança". Ele ressaltou que é quase impossível fazer projeções. "Eu, particularmente, não enxergo no sistema, devido às suas limitações fonológicas, chances de isso acontecer". Em meio às considerações finais, Ana Paula conseguiu retornar a conversa, após problemas com a conexão de internet e problematizou a dicotomia entre mobilização versus normatização. Conforme a professora, todas as tentativas de inclusão devem ser valorizadas. "Apesar de os linguistas dizerem que os neutros não são eficazes, não produzem contrastes, o sujeito vai dizer assim: resolve para mim, me satisfaz".

Para finalizar essa resenha, retomo as perguntas iniciais "O português é uma língua que privilegia o gênero gramatical masculino?"; "Se sim, quais as alternativas para promover a inclusão de gêneros sociais menos favorecidos ou até mesmo não contemplados? "; "Diante isso, podemos afirmar que existe gênero neutro em português? ". Conforme as contribuições e reflexões oriundas do encontro online do dia 14, a língua portuguesa apresenta uma predominância do gênero masculino no discurso e, além disso, percebesse que, muitas vezes, as palavras recebem um significado pejorativo ao serem relacionadas a figura feminina. Com o objetivo de resolver esses problemas, as formas de neutralização da língua estão se popularizando entre alguns grupos e ativistas. No entanto, apresentam algumas deficiências. O @, por exemplo, é fortemente criticado por se constituir de uma vogal "o" em torno de um "a", reafirmando a binariedade nos gêneros.

Assim como a estudiosa Ana Paula, acredito que todas as tentativas de inclusão devem ser consideradas. Ao mesmo passo que estou ciente que mudar a língua não vai resolver o preconceito real, vale a pena considerar a busca por espaços sociais. Mesmo que uso de uma linguagem neutra inclusiva não elimine as discriminações sexistas e de gênero na sociedade, a busca por uma neutralidade de gênero na língua traduz uma demanda afetiva e social que deve ser respeitada.

\section{REFERÊNCIAS}

LíNGUA, gramática, gênero e inclusão. Simpósio apresentado por Raquel Freitag [s.l., s.n.], 2020. 1 vídeo (2h 50min 05s). Publicado pelo canal da Associação Brasileira de Linguística. Disponível em: https://www.youtube.com/watch?v=_AdQFP3ssAY. Acesso em: 14 ago 2020. 